\title{
A percepção dos cuidadores de pacientes com necessidades especiais na higiene bucal em um município baiano
}

\author{
The Perception of Caregivers of Patients With Special \\ Needs in Oral Hygiene in A Bahia Municipality
}

\author{
Hugo MARTINS SILVA ${ }^{1}$ \\ KaRINE BRASILEIRO DE OLIVEIRA ${ }^{2}$ \\ ROGÉRIO VIEIRA SILVA ${ }^{3}$ \\ Patrícia Maria Coelho ${ }^{4}$
}

\begin{abstract}
RESUMO
Objetivo: Identificar os conhecimentos de saúde bucal dos cuidadores de Pacientes com Necessidades Especiais em instituições de um município de médio porte da Bahia.

Métodos: Trata-se de investigação de corte transversal, descritiva e analítica com coleta de dados por meio de formulário de pesquisa com questões objetivas e linguagem clara. Os dados foram tabulados e analisados por intermédio do Bioestat 5.3, obtendo-se frequências absolutas e relativas.

Resultados: Foram predominantes os questionários respondidos na Associação dos Pais e Amigos dos Excepcionais (84,6\%), com cuidadores do gênero feminino (95,4\%), 81,5\% eram pais dos atendidos, com renda mensal de um salário mínimo (56,9\%). Em relação à qualidade da saúde bucal, $43 \%$ responderam regular, $58,5 \%$ disseram que placa bacteriana é uma camada formada sobre os dentes, que a cárie é causada pela ação de bactérias que produzem ácidos $46,2 \%$ e $98,5 \%$ afirmaram que a saúde bucal reflete na saúde geral. Dos entrevistados, $38,5 \%$ realizam a higiene bucal três vezes ao dia. Sobre a existência de materiais e técnicas eficientes, para os Pacientes com Necessidades Especiais, 52,4\% acreditam que existam e $67,7 \%$ disseram não conhecer, $43,1 \%$ dos cuidadores relataram ser fácil abrir e manter a boca aberta durante a higienização e $75,4 \%$ não conhecem e não fazem uso de abridores de boca, $84,6 \%$ fazem uso de escova comum e $78,5 \%$ não utilizam o fio dental.

Conclusão: A maioria dos cuidadores de Pacientes com Necessidades Especiais não detém conhecimentos suficientes sobre técnicas e materiais apropriados para higienização da cavidade bucal, o que pode comprometer a promoção da saúde geral desses indivíduos.
\end{abstract}

Palavras-chave: Pessoas com Deficiência. Higiene Bucal. Saúde Bucal.

\section{ABSTRACT}

Objective: To identify the knowledge of oral health from caregivers of Patients with Special Needs (PSN) in a medium-sized town of Bahia.

Methods: This is a cross-sectional, descriptive and analytics research with data collection through search form with objective and clear language issues. The data was tabulated and analyzed through Bioestat 5.3, with absolute and relative frequencies. Results: Were prevalent search form answered in the APAE (84.6\%), caregivers with female gender $(95.4 \%), 81.5 \%$ were parents of the treated, with monthly income of minimum wage $(56.9 \%)$. In regard to the quality of oral health, $43 \%$ responded it was regular, $58.5 \%$ said that bacterial plaque is a layer formed on the teeth, the tooth decay is caused by bacteria that produce acids $46.2 \%$ and $98.5 \%$ stated that the oral health reflects on overall health. Of responded persons, $38.5 \%$ realize the oral hygiene of the patients 3 times a day. About the existence of efficient materials and techniques, for patients with special needs, $52.4 \%$ believe they exist and $67.7 \%$ said not knowing, $43.1 \%$ of caregivers reported be easy to open and maintain mouth open during oral cleaning and $75.4 \%$ do not know and do not make use of mouth openers, $84.6 \%$ make use of common brush and $78.5 \%$ do not use dental floss.

Conclusion: Most of the caregivers of Patients with Special Needs does not have sufficient knowledge about techniques and suitable materials for hygiene of the oral cavity, which can compromise in promoting overall health of these individuals.

Key-Words: People with Disabilities. Oral Hygiene. Oral Health.

\footnotetext{
${ }^{1}$ Graduado em Odontologia. Faculdade Independente do Nordeste - FAINOR.

${ }^{2}$ Especialista em atendimento a Pacientes com Necessidades Especiais e em Saúde Coletiva - São Leopoldo Mandic.

${ }^{3}$ Mestre e Doutor em Endodontia - Pontifícia Universidade Católica/Minas Gerais (PUC-MG). Docente da FAINOR.

${ }^{4}$ Mestre em clínicas odontológicas com ênfase em radiologia - Pontifícia Universidade Católica/Minas Gerais (PUC-

$M G)$. Docente da FAINOR.
} 


\section{INTRODUÇÃO}

A compreensão que os indivíduos têm sobre a condição bucal é uma importante referência à qualidade de vida, que simboliza um compromisso pessoal para a obtenção de uma vida saudável e faz síntese às condições concretas de saúde, às respostas subjetivas, aos valores e às perspectivas culturais. $O$ indivíduo acometido por alterações no estado de saúde geral preocupa-se mais com a disfunção existente, razão pela qual ele se encontra acamado, internado ou limitado e considera irrelevantes os cuidados com a saúde bucal. Por essa razão, é de grande valia que haja a participação do cirurgiãodentista na equipe multidisciplinar para realizar atividades terapêuticas, preventivas e educativas no âmbito da promoção de saúde bucal e, em consequência, na melhoria do quadro geral do paciente..$^{1,2,3}$

Pacientes com Necessidades Especiais (PNEs) são todos aqueles que se desviam social, emocional, intelectual ou fisicamente do que é conceituado como normais em relação aos padrões de crescimento e desenvolvimento e, por isso, necessitam de educação especial, instrução suplementar e serviços adaptados, durante um período, ou por toda sua vida. ${ }^{22}$

Existem PNEs com capacidade de fazer suas tarefas cotidianas, enquanto outros requerem o auxílio de cuidadores para que possam realizálas. Geralmente, as mães assumem o papel de cuidador, pois estas mantêm um convívio diário junto ao paciente e possuem ligação afetiva com o mesmo, no entanto, a função de cuidador também pode ser exercida por outros familiares ou por pessoas especializadas na prática de cuidar. Entre os afazeres diários dos cuidadores, merece destaque a cavidade bucal, onde os procedimentos de higienização são indispensáveis na prevenção das variadas doenças. ${ }^{4,5}$

Um agente importante na ação contra o desenvolvimento das doenças periodontais e da cárie dentária em PNEs é a remoção constante e efetiva da placa bacteriana. Assim sendo, faz-se imprescindível o aprimoramento das estratégias de remoção dessa placa bacteriana por meio de instrumentos de ajuda, como o uso de utensílios coadjuvantes que diminuam as dificuldades referentes aos processos de higienização bucal, visto que, devido a essas dificuldades, a prevalência de doenças bucais é uma problemática significativamente elevada. , $^{4,6}$,

Fatores como condição socioeconômica, limitações resultantes da deficiência, consumo constante de alimentos com sacarose, medicação de uso frequente, alto custo terapêutico, falta de profissionais capazes para a realização do atendimento e as dificuldades para fazer a higiene bucal pelos cuidadores e pelos próprios pacientes, estão presentes nos índices que caracterizam a alta prevalência de distúrbios bucais em PNEs. A qualidade da higiene bucal está relacionada ao quadro clínico do paciente, sendo que indivíduos com problemas de motricidade e inteligência mostram, geralmente, higiene bucal comprometida. Desse modo, possuem maior predominância de cárie dentária, de doenças periodontais e de grande número de dentes não tratados e perdidos. ${ }^{7,8,9}$

Constantemente os cuidadores sentemse desmotivados por não possuírem instruções de como realizar uma higiene bucal adequada e ainda mencionam dificuldades para desempenhá-la. Essas dificuldades estão relacionadas com o manuseio desses indivíduos, visto que podem apresentar limitações motoras, comportamentos violentos e falta de interesse em colaborar. Muitos dos cuidadores declaram que, com as orientações aprendidas, conseguem superar parte das dificuldades no auxílio do PNE no processo de higienização bucal. ${ }^{10,11,12}$

Nesse contexto, a intervenção do cirurgiãodentista mostra-se importante não apenas no atendimento clínico terapêutico especializado, 
mas também no que diz respeito sobre a transmissão de informações fundamentais inerentes aos cuidados adaptados aos PNEs, demonstrando e recomendando instrumentos facilitadores e, simultaneamente, incentivando os cuidadores acerca da importância de uma higienização oral contínua.

Diante do exposto, o objetivo deste estudo foi identificar os conhecimentos de saúde bucal dos cuidadores de PNEs em duas instituições no município de Vitória da Conquista, Bahia (médio porte), a fim de ressaltar a importância da higienização adequada utilizando instrumentos e métodos capazes de potencializá-la.

\section{Métodos}

Previamente à coleta de dados, o estudo foi aprovado pelo comitê de ética e pesquisa (CEP) da Faculdade Independente do Nordeste, sob o parecer CAAE 69626417.3.0000.5578 e seguiu todos os preceitos da bioética estabelecidos pela Resolução 466/12 do Conselho Nacional de Saúde.

Refere-se a uma investigação de corte transversal, descritiva e analítica. A princípio, teve a intenção de identificar os conhecimentos de higiene bucal dos cuidadores de PNEs em instituições do município de Vitória da Conquista, Bahia.

A população de referência da vigente investigação constituiu-se de 65 cuidadores divididos entre os serviços da Associação de Pais e Amigos dos Excepcionais (APAE) e da Faculdade Independente do Nordeste (FAINOR). Esses PNEs estavam sendo assistidos na Clínica Escola de Odontologia da FAINOR e na APAE por meio da escola especializada e do núcleo de tratamento multidisciplinar do Sistema Único de Saúde da associação. Os cuidadores participantes deveriam estar sob os seguintes critérios de inclusão: ser cuidador de indivíduos que possuam deficiências e falta de domínio motor, fazendo que estes dependam de auxílio para realizar a higienização inerente à cavidade bucal, e os critérios de exclusão: cuidadores que também têm deficiências físicas ou intelectuais ou que não participam da higiene bucal da pessoa que está sob os seus cuidados. Todos os cuidadores de PNEs foram convidados a participar da pesquisa, no ano de 2017.

Para maior efetividade da coleta dos dados, foi realizado estudo piloto com $10 \%$ do total da amostra de cuidadores de PNEs disponíveis para investigação, nas mesmas instituições escolhidas para a pesquisa, visando esclarecer possíveis carências no questionário e ajustá-las em tempo hábil. A coleta dos dados se fez por meio de um formulário de pesquisa desenvolvido para este estudo, sob a forma de entrevista direta que continha 19 questões, objetivas e de fácil entendimento, sobre os dados gerais dos voluntários e questões que classificavam o conhecimento acerca da saúde bucal, abordando a temática da avaliação. Foi observado que não houve dificuldade de entendimento por parte dos respondentes durante a aplicação do estudo piloto, no entanto, por uma questão didática, a disposição das questões no formulário foi modificada a fim de padronizar as assertivas. Durante a entrevista, foram usadas imagens ilustrativas com a finalidade de auxiliar no entendimento sobre os materiais modificados e adaptados à higiene bucal de PNEs. O questionário foi aplicado por um único entrevistador devidamente treinado, a fim de que não houvesse comprometimento do estudo ou indução das respostas.

A pesquisa foi realizada por amostra de conveniência, visto que, mesmo com um número elevado de pacientes cadastrados nos serviços da APAE, a abstenção e infrequência dos usuários foram os principais inconvenientes para uma coleta de dados maior. Na FAINOR, poucos respondentes se enquadravam nos critérios de inclusão.

Os dados obtidos foram tabulados em planilhas Excel e submetidos à análise estatísti- 
ca descritiva por meio do programa Bioestat 5.3 , onde se contemplou frequências absolutas, relativas e valores de medianas (mínimo-máximo).

\section{Resultados}

Este estudo foi composto por 65 cuidadores, sendo que $15,4 \%$ deles se encontravam na Faculdade Independente do Nordeste e $84,6 \%$ na Associação de Pais e Amigos dos Excepcionais de Vitória da Conquista. Destes, 95,4\% eram do gênero feminino e, em relação ao grau de parentesco, $81,5 \%$ eram pais dos atendidos. A renda mensal de maior preponderância foi de 1 salário mínimo $(56,9 \%)$ e quanto ao grau de escolaridade dos entrevistados, 49,2\% não tinham nível médio completo. A maioria $(72,3 \%)$ relatou que sempre utiliza os serviços oferecidos pelas instituições onde eles estavam alocados (Tabela 1).

Em relação à qualidade da saúde bucal do indivíduo que cuida, $43 \%$ responderam "regular" para esse conceito. Sobre o que é placa bacteriana, $58,5 \%$ disseram que é "uma camada de bactérias formadas sobre os dentes" e sobre a etiologia da doença cárie, $46,2 \%$ relataram que esta é "causada pela ação de bactérias que produzem ácidos que destroem as camadas dos dentes". A maioria $(98,5 \%)$ afirmou que a saúde bucal interfere na qualidade da saúde geral (Tabela 2).

Dos cuidadores entrevistados, 38,47\% disseram que realizam a higiene da cavidade bucal três vezes ao dia e apenas um afirmou que não faz $(1,5 \%)$. Em relação à existência de materiais e técnicas que podem ser usados em PNEs com eficiência, 52,4\% disseram "sim" e 44,61\% não souberam opinar. Ainda a respeito de conhecer ou fazer uso de materiais e técnicas, $67,7 \%$ dos componentes da amostra disseram não conhecer. Sobre o grau de dificuldade em abrir e manter aberta a boca
Tabela 1. Perfil sociodemográfico dos cuidadores dos Pacientes com Necessidades Especiais.

\begin{tabular}{|c|c|c|c|}
\hline Perguntas & Respostas & $\begin{array}{l}\text { Número } \\
\text { (amostra) }\end{array}$ & $\begin{array}{c}\text { Porcentagem } \\
(\%) \\
\end{array}$ \\
\hline Instituição & $\begin{array}{l}\text { FAINOR } \\
\text { APAE }\end{array}$ & $\begin{array}{l}10 \\
55 \\
\end{array}$ & $\begin{array}{l}15,4 \\
84,6 \\
\end{array}$ \\
\hline Gênero & $\begin{array}{l}\text { Masculino } \\
\text { Feminino } \\
\end{array}$ & $\begin{array}{c}3 \\
62 \\
\end{array}$ & $\begin{array}{c}4,6 \\
95,4 \\
\end{array}$ \\
\hline Parentesco & $\begin{array}{c}\text { Pais } \\
\text { Irmãos } \\
\text { Tios } \\
\text { Avós } \\
\text { Cuidador } \\
\text { Outros } \\
\end{array}$ & $\begin{array}{c}53 \\
4 \\
2 \\
4 \\
1 \\
1 \\
\end{array}$ & $\begin{array}{c}81,5 \\
6,2 \\
3,1 \\
6,2 \\
1,5 \\
1,5\end{array}$ \\
\hline Renda Mensal & $\begin{array}{c}1 \text { salário } \\
2 \text { a } 3 \\
4 \text { a } 5 \\
6 \text { a } 7 \\
8 \text { a } 9 \\
10 \text { acima }\end{array}$ & $\begin{array}{c}37 \\
23 \\
4 \\
0 \\
0 \\
1\end{array}$ & $\begin{array}{c}56,9 \\
35,4 \\
6,2 \\
0,0 \\
0,0 \\
1,5\end{array}$ \\
\hline $\begin{array}{l}\text { Grau de } \\
\text { Instrução }\end{array}$ & $\begin{array}{l}\text { Fund. incompleto } \\
\text { Fund. completo } \\
\text { Médio } \\
\text { incompleto } \\
\text { Médio completo } \\
\text { Sup. Incompleto } \\
\text { Sup. completo }\end{array}$ & $\begin{array}{c}16 \\
8 \\
8 \\
19 \\
8 \\
6\end{array}$ & $\begin{array}{c}24,6 \\
12,3 \\
12,3 \\
29,2 \\
12,3 \\
9,2\end{array}$ \\
\hline $\begin{array}{l}\text { Frequência de } \\
\text { Utilização dos } \\
\text { Serviços }\end{array}$ & $\begin{array}{c}\text { Sempre } \\
\text { Frequentemente } \\
\text { Raramente }\end{array}$ & $\begin{array}{c}47 \\
18 \\
0\end{array}$ & $\begin{array}{c}72,3 \\
27,7 \\
0,0\end{array}$ \\
\hline
\end{tabular}

no momento da higienização, $43,07 \%$ dos cuidadores relataram ser "difícil" e 40\%, "fácil". Sobre conhecer ou fazer uso de abridores de boca na higienização, 75,4\% não conhecem e $16,9 \%$ conhecem e não o fazem. Sobre escovas de dente, $84,6 \%$ declararam fazer uso de "escova comum" e 49,3\% acreditam que a escova motorizada seria a melhor opção para aperfeiçoar a higiene bucal. Em relação ao uso do fio dental na higienização da boca, $78,46 \%$ relataram não fazer uso e acerca das diferentes formas de fios dentais, $86,2 \%$ assumiram não conhecer e 10,8\% conheciam, mas não faziam uso (Tabela 3). 
Tabela 2. Avaliação dos conhecimentos gerais sobre saúde bucal dos cuidadores de Pacientes com Necessidades Especiais.

\begin{tabular}{|c|c|c|c|}
\hline Perguntas & Respostas & Número (amostra) & Porcentagem (\%) \\
\hline $\begin{array}{l}\text { Classificação } \\
\text { da saúde } \\
\text { bucal }\end{array}$ & $\begin{array}{l}\text { Ótimo } \\
\text { Bom } \\
\text { Regular } \\
\text { Ruim } \\
\text { Não sei }\end{array}$ & $\begin{array}{l}4 \\
24 \\
28 \\
9 \\
0\end{array}$ & $\begin{array}{l}6,2 \\
37,0 \\
43,0 \\
13,8 \\
0,0\end{array}$ \\
\hline $\begin{array}{c}\text { O que é placa } \\
\text { bacteriana? }\end{array}$ & $\begin{array}{c}\text { Barreira com a função de impedir a multiplicação de bactérias } \\
\text { Camada de bactérias formada nos dentes } \\
\text { Placa para estudo de bactérias } \\
\text { Não sei }\end{array}$ & $\begin{array}{c}3 \\
38 \\
1 \\
23\end{array}$ & $\begin{array}{c}4,6 \\
58,5 \\
1,5 \\
35,4\end{array}$ \\
\hline $\begin{array}{l}\text { Como ocorre } \\
\text { a doença } \\
\text { cárie? }\end{array}$ & $\begin{array}{c}\text { Somente por meio da alimentação } \\
\text { Ocorre quando o dente quebra ou é frágil } \\
\text { Ocorre pela ação de bactérias que produzem ácidos e destroem } \\
\text { as camadas dos dentes } \\
\text { Não sei }\end{array}$ & $\begin{array}{l}21 \\
6 \\
30 \\
8\end{array}$ & $\begin{array}{l}32,3 \\
9,2 \\
46,2 \\
12,3\end{array}$ \\
\hline $\begin{array}{l}\text { Saúde bucal } \\
\quad x \\
\text { Saúde geral }\end{array}$ & $\begin{array}{l}\text { Sim } \\
\text { Não } \\
\text { Não sei }\end{array}$ & $\begin{array}{c}64 \\
0 \\
1\end{array}$ & $\begin{array}{l}98,5 \\
0,0 \\
1,5\end{array}$ \\
\hline
\end{tabular}

Tabela 3. Avaliação dos conhecimentos específicos em saúde bucal aos cuidadores dos pacientes com necessidades especiais.

\begin{tabular}{|c|c|c|c|}
\hline Perguntas & Respostas & Número (amostra) & Porcentagem (\%) \\
\hline Frequência de higienização bucal & $\begin{array}{c}1 \text { vez ao dia } \\
2 \text { vezes ao dia } \\
3 \text { vezes ao dia } \\
\text { Não possui } \\
\text { frequência fixa } \\
\text { Não faz }\end{array}$ & $\begin{array}{c}6 \\
19 \\
25 \\
14 \\
1\end{array}$ & $\begin{array}{c}9,25 \\
29,24 \\
38,47 \\
21,55 \\
1,5\end{array}$ \\
\hline $\begin{array}{c}\text { Acredita que existem materiais e técnicas } \\
\text { que podem ser usados em PNEs com } \\
\text { eficiência? }\end{array}$ & $\begin{array}{l}\text { Sim } \\
\text { Não } \\
\text { Não sei }\end{array}$ & $\begin{array}{l}34 \\
2 \\
29\end{array}$ & $\begin{array}{c}52,4 \\
3,08 \\
44,61\end{array}$ \\
\hline $\begin{array}{l}\text { Conhece ou já fez uso de algum instrumento } \\
\text { que facilite a limpeza da boca dos PNEs? }\end{array}$ & $\begin{array}{l}\text { Conheço e já fiz uso } \\
\text { Conheço e não fiz uso } \\
\text { Não Conheço }\end{array}$ & $\begin{array}{l}9 \\
12 \\
44\end{array}$ & $\begin{array}{l}13,85 \\
18,45 \\
67,7\end{array}$ \\
\hline $\begin{array}{c}\text { Classificação dos níveis de dificuldade em } \\
\text { abrir e manter aberta a boca da pessoa } \\
\text { cuidada }\end{array}$ & $\begin{array}{l}\text { Muito Difícil } \\
\text { Difícil } \\
\text { Fácil } \\
\text { Muito Fácil }\end{array}$ & $\begin{array}{c}6 \\
28 \\
26 \\
5\end{array}$ & $\begin{array}{l}9,23 \\
43,07 \\
40 \\
7,7\end{array}$ \\
\hline $\begin{array}{c}\text { Conhece ou faz uso de algum abridor de } \\
\text { boca durante a higienização bucal? }\end{array}$ & $\begin{array}{l}\text { Conheço e faço uso de todos } \\
\text { Conheço e faço uso de um } \\
\text { Conheço e não faço uso } \\
\text { Não conheço }\end{array}$ & $\begin{array}{l}0 \\
5 \\
11 \\
49\end{array}$ & $\begin{array}{c}0,0 \\
7,7 \\
16,9 \\
75,40\end{array}$ \\
\hline Qual tipo de escova de dente você faz uso? & $\begin{array}{l}\text { Escova comum } \\
\text { Escova especial } \\
\text { Nenhuma }\end{array}$ & $\begin{array}{c}55 \\
9 \\
1\end{array}$ & $\begin{array}{c}84,6 \\
13,9 \\
1,5\end{array}$ \\
\hline $\begin{array}{l}\text { Qual desses tipos de escova você acredita } \\
\text { que facilitaria a higiene bucal? }\end{array}$ & $\begin{array}{c}\text { Escova com cabo anatômico } \\
\text { Escova com cabo adaptado } \\
\text { Escova motorizada }\end{array}$ & $\begin{array}{c}24 \\
9 \\
32\end{array}$ & $\begin{array}{l}36,9 \\
13,8 \\
49,3\end{array}$ \\
\hline Faz uso de fio dental? & $\begin{array}{l}\text { Sim } \\
\text { Não } \\
\text { Não sei }\end{array}$ & $\begin{array}{c}14 \\
51 \\
0\end{array}$ & $\begin{array}{c}1,54 \\
78,46 \\
0,0\end{array}$ \\
\hline $\begin{array}{l}\text { Quais desses fios dentais } \\
\text { conhece ou faz uso? }\end{array}$ & $\begin{array}{c}\text { Conheço e faço uso de todos } \\
\text { Conheço e faço uso de um } \\
\text { Conheço e não faço uso } \\
\text { Não conheço }\end{array}$ & $\begin{array}{r}0 \\
2 \\
7 \\
56\end{array}$ & $\begin{array}{l}0,0 \\
3 \\
10,8 \\
86,2\end{array}$ \\
\hline
\end{tabular}




\section{Dıscussão}

Para a Organização Mundial da Saúde (OMS), Pacientes com Necessidades Especiais são os indivíduos que apresentam alguma disfuncionalidade, que resultam em limitações nas atividades cotidianas e restrições no convívio social. Em situações que o PNE não tem domínio motriz e cognitivo para realizar as funções de higienização por conta própria, estas são executadas por outra pessoa que assume o papel de cuidador. Portanto, torna-se relevante este estudo que identificou os conhecimentos de higiene bucal dos cuidadores de PNEs no município de Vitória da Conquista, Bahia. 13,14,15,16

Nasiloski et al. ${ }^{11}$ relataram que, em $85 \%$ dos casos, o papel de cuidador é exercido pela mãe, fato reforçado por Campanaro et al. ${ }^{17}$ Neste estudo, muitos dos cuidadores são do gênero feminino $(95,4 \%)$ e $81,5 \%$ se identificaram como mãe da pessoa que estava sob os seus cuidados. Esse dado reforça a importância da sensibilização da família, especialmente as mães, sobre a aplicação de materiais e técnicas na higiene bucal de PNEs, o que pode resultar em benefícios e deve ser a primeira medida para garantir a saúde bucal desses pacientes. ${ }^{18}$

Em relação à renda familiar mensal e ao grau de instrução, a associação entre as condições socioeconômicas e o grau de escolaridade tem sido observada em alguns estudos onde sugerem que há uma prevalência maior de cárie e doenças bucais nos indivíduos que possuem baixos níveis financeiros e de escolaridade. No vigente estudo, 36,9\% do percentual de respondentes possuía ensino fundamental entre completo e incompleto e $9,2 \%$ ensino superior completo. Esses resultados podem sugerir que há correlação entre os níveis financeiros e de escolaridade, pois o desconhecimento acerca de cuidados bucais ressalta a necessidade de capacitar esses cuidadores por meio de ações educativas. ${ }^{11,19,20,21}$
Apesar da importância de consultas odontológicas regulares e apropriadas, a OMS relata que somente $3 \%$ da população total de deficientes tem acesso a tratamentos odontológicos. Corroborando com essa afirmativa, estudos mostraram que as crianças com comprometimentos físicos ou mentais mais severos têm ainda menos chances de contato com os serviços odontológicos. Neste estudo, quando perguntados sobre a frequência de utilização dos serviços prestados pela instituição que estavam alocados, $72,3 \%$ dos cuidadores de PNEs disseram que sempre o utilizam. A escolha foi por amostra de conveniência, apesar da pesquisa contemplar um bom número absoluto, foi uma limitação encontrada, o que pode estar relacionado à dificuldade do acesso e deslocamento dessa população aos serviços. Isso sugere que a adesão ao tratamento especializado é feita apenas por uma pequena parcela da população que, apesar da necessidade, encontra outras dificuldades cotidianas que lhe impedem de prosseguir o tratamento. ${ }^{11,21}$

No que se refere à classificação da condição de saúde bucal, $43 \%$ dos cuidadores participantes deste estudo optaram por "regular" e $37 \%$ "bom". As classificações "ótimo" e "ruim" tiveram 6,2\% e 13,8\%, respectivamente. A análise dessas escolhas sugere que o cuidador talvez não seja capaz de identificar a real condição de saúde bucal do indivíduo que cuida, seja pelo grau de escolaridade ou pela relação de afeto que tem com o $\mathrm{PNE}$, visto que o percentual de escolhas entre uma assertiva e outra não é elevado, isso intensifica a necessidade de um profissional capacitado na assistência à saúde bucal dos PNEs, aprimorando os conhecimentos desses cuidadores para esta definição de forma mais consistente..$^{15,21}$

Os pacientes com deficiência são considerados de risco para as doenças bucais. Estudo realizado por Nasiloski et al. ${ }^{11}$ constatou que $85 \%$ dos pacientes apresentaram uma quan- 
tidade de placa bacteriana madura, e isso se deve ao desconhecimento sobre os malefícios que a mesma pode causar. Neste estudo, ao serem questionados sobre o que é placa bacteriana, $35,4 \%$ disseram não saber do que se trata, o que torna este um dado preocupante no que se refere à qualidade da saúde desses indivíduos. A remoção diária e eficiente da placa bacteriana é um elemento importante para impedir o desenvolvimento de cárie dentária e doença periodontal. Esses esclarecimentos deveriam compor o cerne dos conhecimentos dos cuidadores. ${ }^{4,16,17}$

Cáries dentárias são complicações frequentes em pacientes com deficiência. Quando o responsável por cuidar da higiene bucal exerce remoção efetiva da placa bacteriana, esse ato torna-se um fator coadjuvante para impedir o desenvolvimento e a progressão da cárie. A maior parte dos entrevistados $(46,2 \%)$ afirmou que a etiologia da cárie dentaria é a "ação de bactérias que produzem ácidos e destroem as camadas dos dentes". Ensinar essa população como controlar fatores etiológicos acrescentaria vantagens aos cuidados especiais. .,23,24,25 $^{2}$

Para Campanaro et al., ${ }^{17}$ a falta de higiene bucal pode gerar implicações negativas na qualidade de vida, tendo potencial para refletir em vários âmbitos da saúde sistêmica do indivíduo. Neste estudo, ao serem perguntados se consideravam a saúde bucal importante para o estado geral de saúde da pessoa que estava sob o seu zelo, 98,5\% disseram que sim, sob a justificativa de que "a saúde começa pela boca”. É um fato imutável que a saúde bucal exerce influência na saúde geral, principalmente em PNEs. Tendo uma visão ampla, pode-se dizer que alterações bucais podem estar relacionadas com o aumento do risco de doenças cardiovasculares, acidentes vasculares cerebrais e doenças respiratórias e com isso influenciar no aumento da taxa de mortalidade. ${ }^{25}$
Vettore et al. ${ }^{25}$ revelam em seu estudo que a frequência de higienização bucal é consideravelmente associada com a higiene corporal e se uma não é posta em prática, por conseguinte haverá desinteresse em exercer a outra. Neste estudo, 38,47\% dos cuidadores relataram que faziam a higiene da boca dos PNEs três vezes ao dia e isso fez-se perceptível pois, mesmo com todas as limitações, havia um comprometimento dos responsáveis em torno da higiene geral dos indivíduos.

Quando usados técnicas e instrumentos que aprimoram a higiene bucal de pessoas com deficiência, resultam em medidas positivas contra a prevalência de doenças bucais. Abridores de boca, fios dentais e escovas modificadas são exemplos de tecnologias que auxiliam e facilitam a higiene bucal. Ao serem perguntados se acreditavam na existência de materiais de higiene bucal voltados aos PNEs, $52,4 \%$ disseram acreditar, no entanto, quando indagados a respeito de conhecer ou fazer uso desses instrumentos, $67,7 \%$ afirmaram que não. Esses resultados retratam que, por muitas vezes, o desconhecimento de técnicas facilitadoras age contrário às melhorias na saúde bucal.

Um dos maiores inconvenientes encontrados pelos cuidadores no momento da higiene bucal está no que se refere ao manejo desses indivíduos. Campanaro et al. ${ }^{17}$ dizem que somente $10 \%$ dos cuidadores declaram efetuar sem problemas a higiene bucal da pessoa sob sua responsabilidade. Nasiloski et al. ${ }^{11}$ mostram em seu estudo que $81,3 \%$ destacam a restrição para abertura de boca como um agravante entre as dificuldades já existentes para a higiene bucal. Neste estudo, 43,03\% dos entrevistados relataram que é difícil abrir e manter aberta a boca da pessoa, durante a escovação, isso reforça a importância do uso dos abridores de boca pelos cuidadores. ${ }^{10}$

Os abridores de boca são artifícios usados quando os PNEs têm dificuldade de manter a 
boca aberta ou não colaboram durante a higiene bucal, no entanto, o uso domiciliar desses utensílios ainda é pouco propagado. Existem no mercado abridores de diversos materiais e alguns autores sugerem que os mesmos sejam confeccionados com materiais de baixo custo. Neste estudo, $75,4 \%$ dos entrevistados disseram não conhecer qualquer dos tipos de abridores apresentados e isso reforça a ideia de que o uso desses instrumentos deve ser divulgado para a comunidade em geral, pois, por meio da orientação, o cuidador pode buscar a superação das dificuldades encontradas durante a higiene bucal de Pacientes com Necessidades Especiais. ${ }^{26,27,28,29,30}$

É sabido que a escovação é o hábito mais comum para a higiene da boca e isso torna a escova de dente o principal artefato na limpeza da cavidade bucal. Quando a técnica de escovação é de boa qualidade, é possível que qualquer escova cumpra com as funções de higienização, no entanto, quando se trata de PNEs, utilizar escovas adaptadas pode facilitar a prática da escovação. Neste estudo, $84,6 \%$ disseram que usam escova comum e, 49,3\% escolheram a escova motorizada como melhor opção para suprimir as necessidades do cuidador. Essa escolha se justifica, pois, as escovas motorizadas possuem grande capacidade de remoção de placa bacteriana e sua praticidade reflete em melhorias na função do cuidador. Vale ressaltar que existem adaptações capazes de melhorar o desempenho da escova de dente comum, quando esta é personalizada à situação de cada cuidador e se torna instrumento seguro e funcional.

O fio dental é primordial para a higiene bucal das áreas onde há contato proximal entre os dentes, regiões as quais a escova dentária não alcança. Nasiloski et al. ${ }^{11}$ constataram que mais de $90 \%$ dos deficientes neuropsicomotores não utilizavam fio dental, alto índice que também foi relatado por Sacchetto et al. ${ }^{30}$ os quais verificaram que $70 \%$ dos entrevistados não possuíam esse hábito. Este estudo corrobora com nossos resultados, pois $78,46 \%$ da amostra não faz uso do fio dental.

O uso do fio dental na sua forma convencional pode não surtir efeito em PNEs, pois muitos indivíduos não conseguem desenvolver as habilidades operacionais necessárias. Das alternativas para o uso do fio dental em PNEs, destaca-se o porta-fio em forma de forquilha, pela possibilidade de usá-lo apenas com uma das mãos. Neste estudo, $86,2 \%$ dos participantes declararam que não conheciam fios dentais adaptáveis aos PNEs, e, ao serem apresentados, $66 \%$ dos cuidadores preferiram o fio em forquilha pela praticidade que este oferece. Esse fato evidencia que os fios dentais apropriados fazem-se necessários e, assim, combinar praticidade e eficiência em busca de uma saúde bucal plena para PNEs. 11,27,30

Observou-se neste estudo que os cuidadores de PNEs podem contribuir para a melhoria da saúde bucal desde que sejam instruídos sobre como proceder corretamente frente à limpeza da boca. É importante que haja sensibilização dos cuidadores para que estes despertem suas atenções aos materiais e métodos e suas aplicações. Ademais, vale a pena ressaltar que estes resultados devem ser divididos com a sociedade a fim de fornecer esclarecimento para os cuidadores.

\section{Considerações Finais}

Com base nos resultados apresentados, mesmo havendo conhecimento em alguns aspectos, os cuidadores de pacientes especiais demonstraram que muitos elementos não são de sua expertise e isso os desafia a desempenhar o papel de cuidar com mais eficiência. Tornou-se evidente, também, que esse grupo encontra-se totalmente receptivo às novas informações que corroborem em melhores práticas de saúde, cujos benefícios 
poderão se perpetuar e refletir na promoção da saúde geral dos indivíduos cuidados.

É importante salientar que as tecnologias relacionadas ao cuidado bucal para PNEs precisam ser difundidas, além de disponibilizar orientações que assegurem a manutenção de uma higiene bucal domiciliar adequada, além do que a instrução contínua nos serviços de saúde e de atenção fortalece o cuidado com base na integralidade, motivando a saúde do PNE. Convém salientar que os dados colhidos são oriundos de autodeclarações e, por isso, é necessária prudência na interpretação dos resultados.

\section{REFERÊNCIAS}

1. Bianco VC, Lopes ES, Borgato MA, Silva PM, Marta SN. O impacto das condições bucais na qualidade de vida de pessoas com cinquenta ou mais anos de vida. Ciênc Saúde Colet. 2010, 15 (4): 2.165-72.

https://www.ncbi.nlm.nih.gov/pubmed/20694338

1. Lima DC, Saliba NA, Garbin AJI, Fernandes LA, Garbin CAS. A importância da saúde bucal na ótica de pacientes hospitalizados. Ciênc Saúde Colet. ABRASCO - Assoc Brasil Saúde Colet. 2011, 16: 1.173-80.

www.scielo.br/scielo.php?script=sci_arttext\&pi $\mathrm{d}=\mathrm{S} 1413-81232011000700049$

2. Lopes EA. A Odontologia hospitalar no Brasil: uma visão do futuro ou um tema atual? Rev Odonto da Univ S Amaro. 1996, 1 (2): 11-4. www.scielo.br/scielo.php?script=sci_arttext\&pi $d=S 1413-81232011000700049$

3. Silveira JLGC, Oliveira V., Padilha WWN. Avaliação da redução do índice de placa e do índice de sangramento gengival em uma prática de promoção de saúde bucal com crianças. Pesq Odonto Bras. 2002, 16 (2): 169-74.

www. lume.ufrgs.br/bitstream/handle/10183/34048/000789997.pdf?...1

4. Guerreiro PO, Garcias GL. Diagnóstico das condições de saúde bucal em portadores de paralisia cerebral do município de Pelotas, Rio Grande do Sul, Brasil. Ciênc e Saúde Colet. 2009, 14 (5): 1.939-46.
www.scielo.br/scielo.php?pid=S141381232009000500036\&script=sci...tlng...

5. Silva NL, Dessen MA. Crianças com Síndrome de Down e suas Interações Familiares. Psico: Reflex e Crít. 2003, 16 (3): 503-51. revistaneurociencias.com.br/edicoes/2007/.../ Pages\%20from\%20RN\%2015\%2004-8.p...

6. Pimentel EL, Azevedo VM, Castro Rde A., Reis LC, De Lorenzo A. Caries experience in young children with congenital heart disease in a developing country. Braz Oral Res. 2013, 27 (2): 103-8.

https://www.ncbi.nlm.nih.gov/pmc/articles/ PMC5111257/

7. Queiroz FS, Rodrigues MMLF; Junior GAC, Oliveira $A B$, Oliveira JD, Almeida ER. Avaliação das condições de saúde bucal de Portadores de Necessidades Especiais. Rev Odonto UNESP. 2014, 43 (6): 396-01.

http://www.scielo.br/pdf/rounesp/ v43n6/1807-2577-rounesp-43-06-0396.pdf

8. Sampaio EF, César FN, Martins MGA. Perfil odontológico dos pacientes portadores de necessidades especiais atendidos no Instituto de Previdência do Estado do Ceará. Rev Bras Prom Saúde. 2004, 17 (3) 127-34.

http://periodicos.unifor.br/RBPS/article/ view/689/2057

9. Flório FM, Basting RT, Salvatto MV, Migliato KL. Saúde bucal em indivíduos portadores de múltiplas deficiências. Rev Gau de Odonto RGO, 2007, 55 (3): 251-56.

www.revistargo.com.br/include/getdoc.php?id= 1232\&article $=748 \&$ mode $=p d f$

10. Nasiloski KS, da Silveira ER, César Neto, JB.; Schardosim, LR. Avaliação das condições periodontais e de higiene bucal em escolares com transtornos neuropsicomotores. Rev Odonto UNESP. 2015, 44 (2): 103-07. www.scielo.br/pdf/rounesp/v44n2/1807-2577-rounesp-44-2-103.pdf

11. Oliveira ALBM, Giro. Importância da abordagem precoce no tratamento odontológico de pacientes com necessidades especiais. 2011, 19 (38): 45-1.

https://www.metodista.br/revistas/revistas-ims/ index.php/Odonto/article/view/2464

12. Farias N, Buchalla CM. A classificação interna- 
cional de funcionalidade, incapacidade e saúde da Organização Mundial da Saúde. Conceitos, usos e perspectivas. Rev Bras Epidemiol. 2005, 8 (2): 187-93.

http://www.scielo.br/pdf/rbepid/v8n2/11.pdf

13. Bizarra MF, Graça SR. O perfil do paciente da consulta para pessoa com necessidades especiais da FDM-UL. Rev Port Estomatol Med Dent Cirur Maxilo-Fac. 2010, 51 (2): 69-74. revista.uepb.edu.br/index.php/pboci/article/ download/1058/780

14. Sampaio EF, César FN, Martins MGA. Perfil odontológico dos pacientes portadores de necessidades especiais atendidos no Instituto de Previdência do Estado do Ceará. Rev Bras Prom Saúde 2004: 17 (3): 127-34. ojs.unifor.br/RBPS/article/view/689

15. Carvalho EMC, Araújo RPC. A saúde bucal em portadores de transtornos mentais e comportamentais. Pesq Bras Odontoped Clin Integ. 2004, jan./abr. 4 (1): 65-75.

pesquisa.bvsalud.org/portal/resource/pt/biblio-872751

16. Campanaro M., Huebner CE, Davis BE. Facilitators and barriers to twice daily tooth brushing among children whit special health care needs. Spec Care Dentist. 2014, jul./ago. 34 (4): 185-92. http://dx.doi.org/10.1111/scd.12057. PMid:24252060

17. Roncalli AG, Côrtes MIS, Peres KG. Perfis epidemiológicos de saúde bucal no Brasil e os modelos de vigilância. Cad. Saúde Púb. 2012, 28 suppl: 558-568.

http://www.scielo.br/pdf/csp/v28s0/07.pdf

18. Bhandary S., Shetty V., Hegde AM, Rai K. Knowledge of care providers regarding the oral health care of visually impaired children. J Clin Pediatr Dent. 2013, 37 (4): 385-9.

h t t p s:// w w w. ncbi.nIm.nih.gov/ pubmed?linkname=pubmed.

19. Gardens SJ, Krishna M., Vellappally S., Alzoman H., Halawany HS, Abraham NB, et al. Oral health survey of 6-12-year-old children with disabilities attending special schools in Chennai, India. Int J Paediat Dent. 2014, nov. 24 (6): 424-33.

https://www.ncbi.nIm.nih.gov/m/ pubmed/24372860
20. Lewis CW. Dental care and children with special health care needs: a population-based perspective. Acad Pediatr. 2009, nov./dez. 9 (6): 420-6. www.academicpedsjnl.net/article/S18762859(09)00253-8/pdf

21. Mugayar LRF. Pacientes portadores de necessidades especiais. Manual da Odontol e Saúd Oral, 1.ed. São Paulo: Pancast, 2000.

22. Moimaz SAS, Saliba NA, Saliba O., Vieira SMM. Saúde bucal e a professora de 10 grau. RGO Rev Gaúcha Odontol. 1992, 40 (4): 295-7.

23. Lee H., So JS, Hochstelder JL, Ercoli C. The accuracy of implant impressions: a systematic review. J Posth Dent. 2008, 285: 91-00.

https://www.ncbi.nlm.nih.gov/pubmed/18922257

24. Vettore MV, Moysés SJ, Sardinha LMV, Moehlecke BPI. Condição socioeconômica, frequência de escovação dentária e comportamentos em saúde em adolescentes brasileiros: uma análise a partir da Pesquisa Nacional de Saúde do Escolar (PeNSE). Cad. Saúde Púb. Rio de Janeiro, 2012 (Suppl 5): 101-13 http://www.ykdent.com.tw/pdf/Overdenture/aii. pdf

25. Peixoto ITA, Rocha CT, Fernandes PM. Auxiliary devices for management of special needs patients during in-office dental treatment or athome oral care. Int J Dent. 2010, 9 (2): 85-9.

http://revodonto.bvsalud.org/scielo. php?script=sci_arttext\&pid=S1806-146X20100 00200006\&lng =en\&nrm=iso\&tlng =en

26. Hartwig AD, Junior IFS, Stuemer VC, Shardosim LR, Azevedo MS. Recursos e técnicas para a higiene bucal dos pacientes com necessidades especiais. Rev. Enf Saú. 2013, 12 (4) 55-1. http://www.rvacbo.com.br/ojs/index.php/ojs/article/view/272

27. Campos CC, Frazão BB, Saddi GL, Morais LA, Ferreira MG, Setúbal PCO, et al. Manual prático para o atendimento odontológico de pacientes com necessidades especiais, 2. ed. Goiânia: Universidade Federal de Goiânia, 2009. https://cvtpcd.odonto.ufg.br/up/299/o/Manual_ corrigido-.pdf

28. Aguiar SMHCA, Alves Rezende MCR. Dental care for cerebral palsy patients using auxiliary resources to inhibit pathological tonic reflexes. Arch Health Invest. 2013, 2 (4): 39-44. 
https://repositorio.unesp.br/bitstream/handle/11449/133476/ISSN2317-3009-2013-02-0439-44.pdf?sequence=1

29. Sacchetto MSLS, Andrade NS, Brito MHSF, Lira DMMP, Barros SLLV. Evaluation of oral health in patients with mental disorders attended at the clinic of oral diagnosis of a public university. Rev Odontol UNESP 2013, set./out. 42 (5): 344-9. http://www.scielo.br/scielo.php?script=sci_artte xt\&pid=S1807-25772013000500005

\section{Anexo A - IMAGENS ABRIDORES DE BOCA}

Imagens ilustrativas para a questão 10
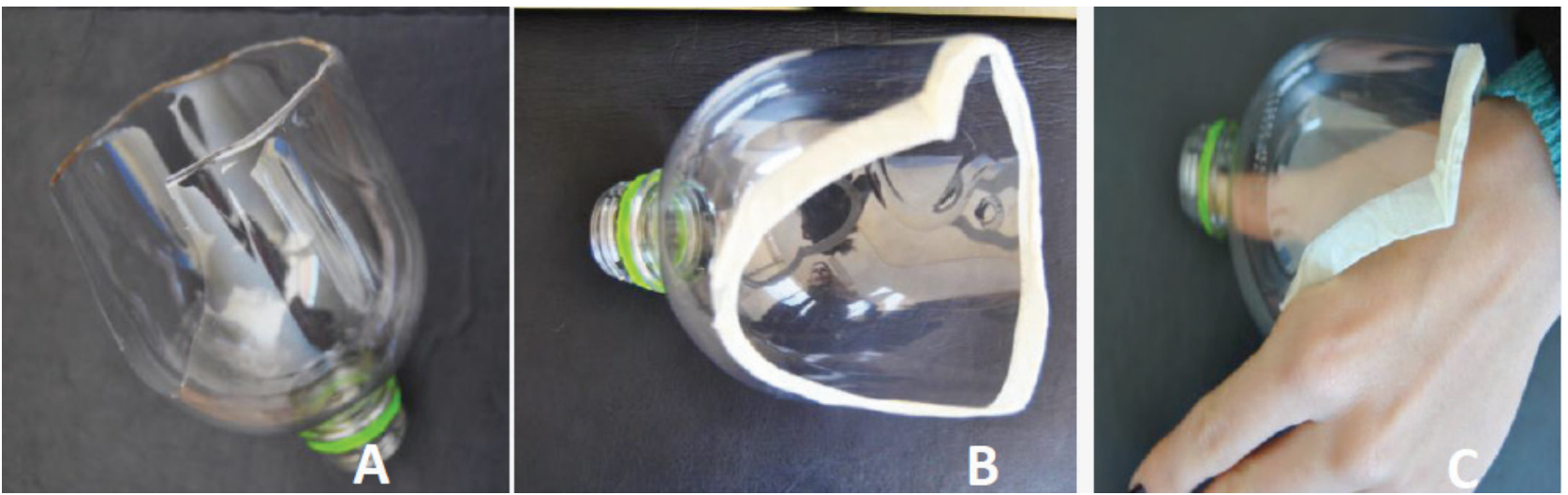

1 - Abridor de boca feito com garrafa PET
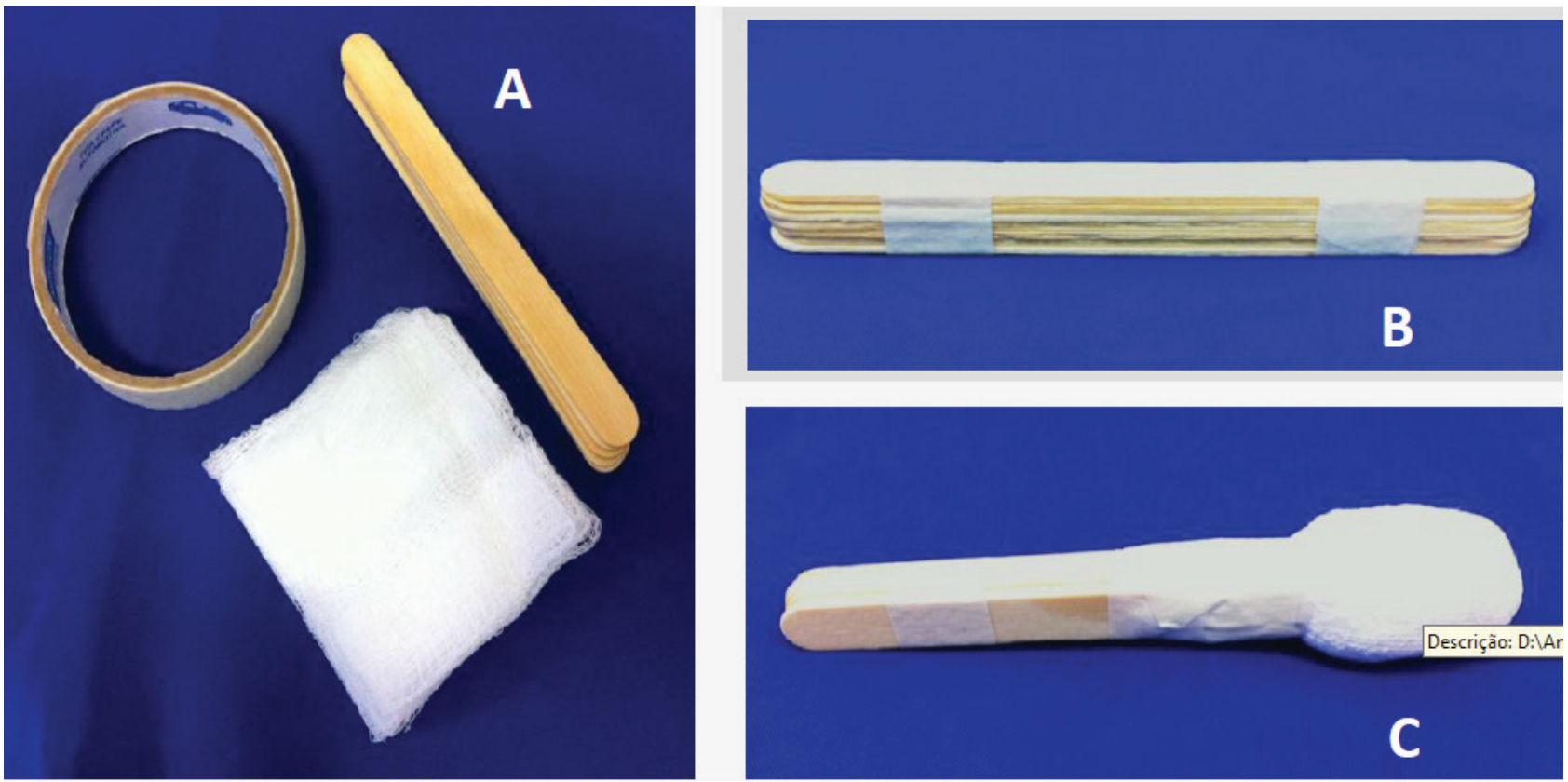

2 - Abridor de boca feito com palito de madeira e gaze 

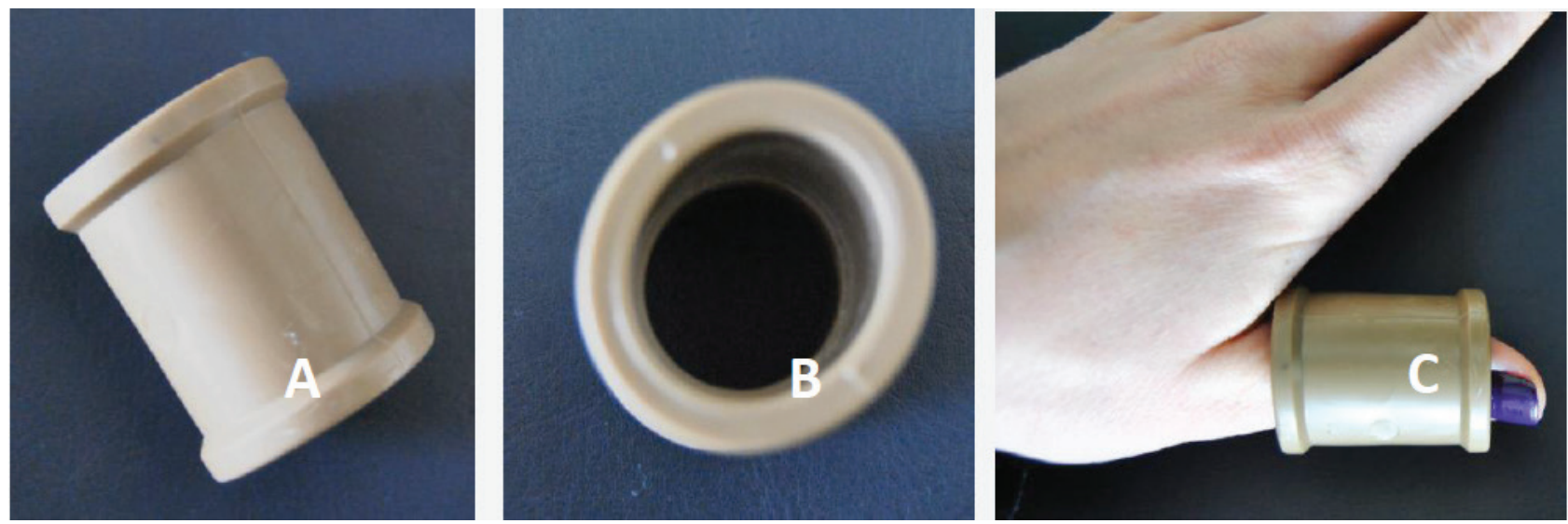

3 - Abridor de boca feito com Cano de PVC

Hartwing AD et al. Recursos e Técnicas para a Higiene Bucal de Pacientes com Necessidades Especiais

\section{ESCOVAS DE DENTE}

Imagens ilustrativas para a questão 12

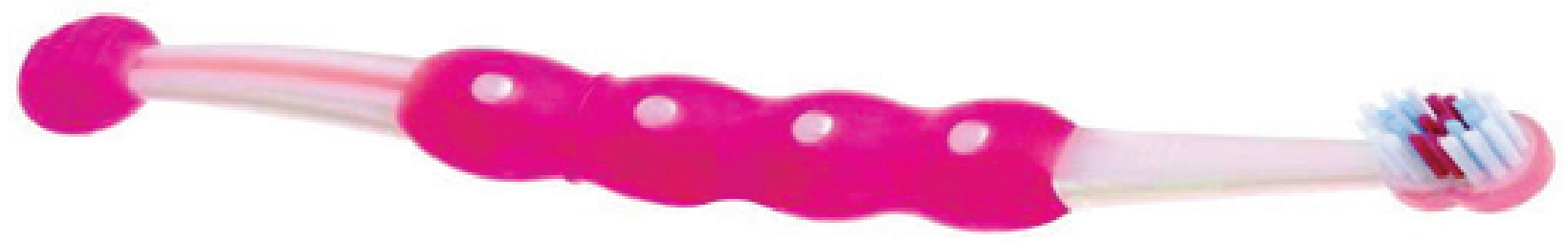

\section{1 - Escova com cabo anatômico}

HTTPS://WWW.ALOBEBE.COM.BR/KIT-COM-2-ESCOVAS-DE-DENTES-GIRLS.HTML, 1861
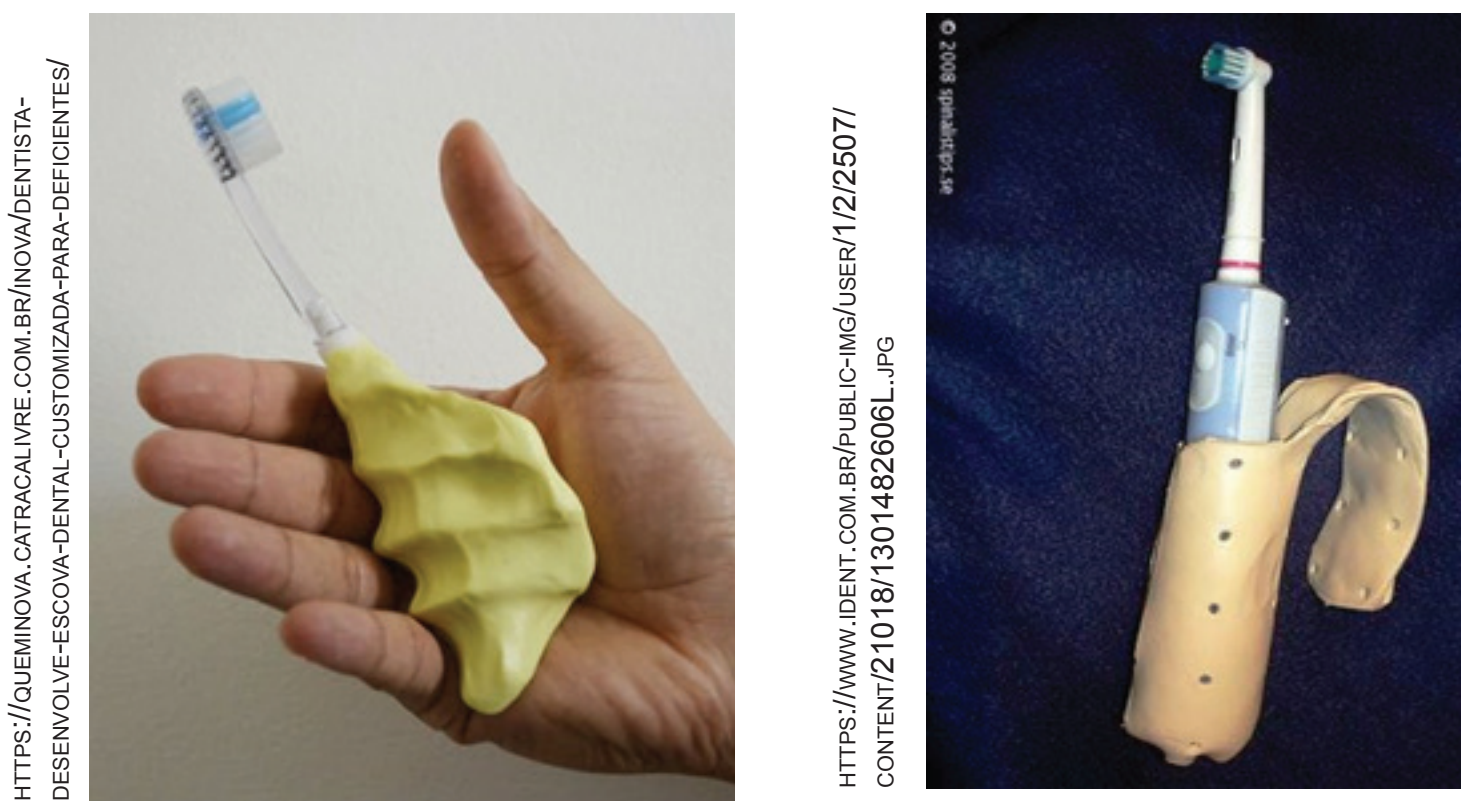

2 - Escova com cabo adaptado 


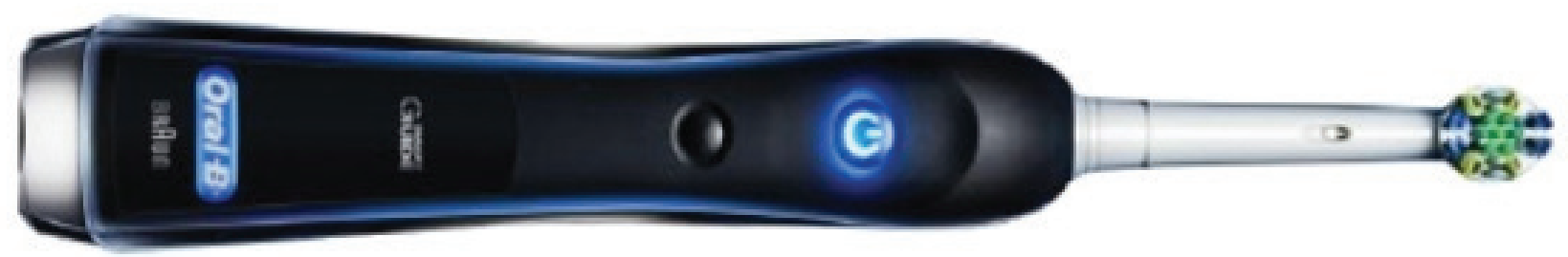

HTTP://WWW.COMPRAFARI.COM/ESCOVA-DE-DENTES-ELETRICA-PRECISION-BLACK-7000-ORAL-B/

\section{3 - Escova motorizada}

\section{FIOS DENTAIS}

Imagens ilustrativas para a questão 14
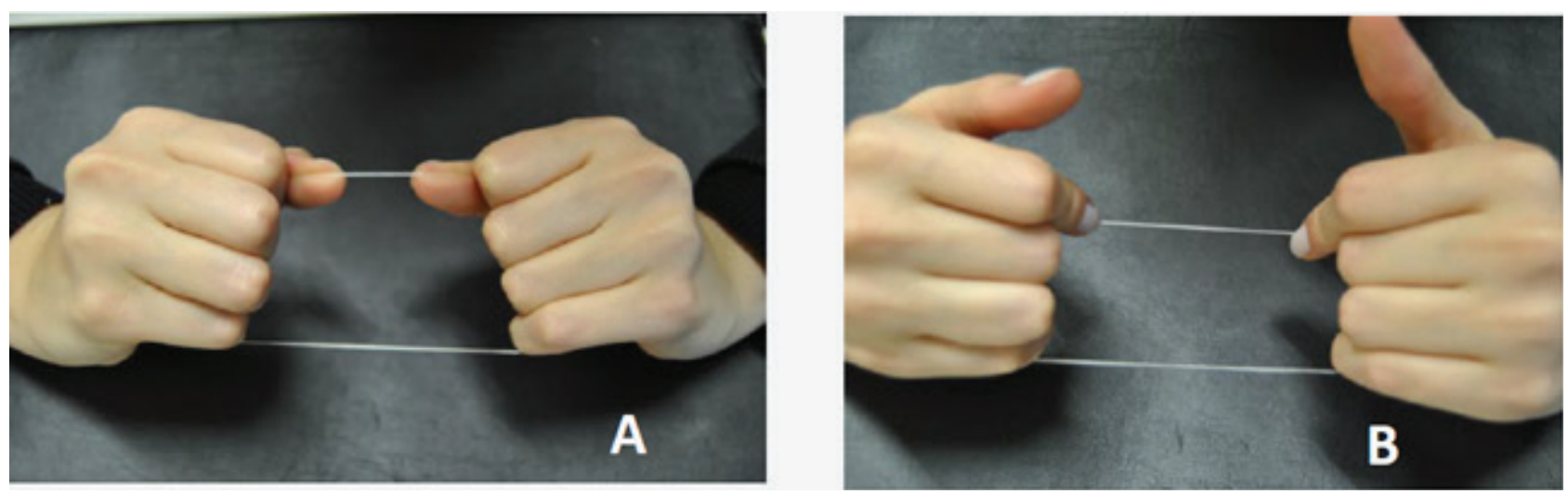

Hartwing AD et al. Recursos e Técnicas para a Higiene Bucal de Pacientes com Necessidades Especiais

1 - Fio-dental na técnica do círculo
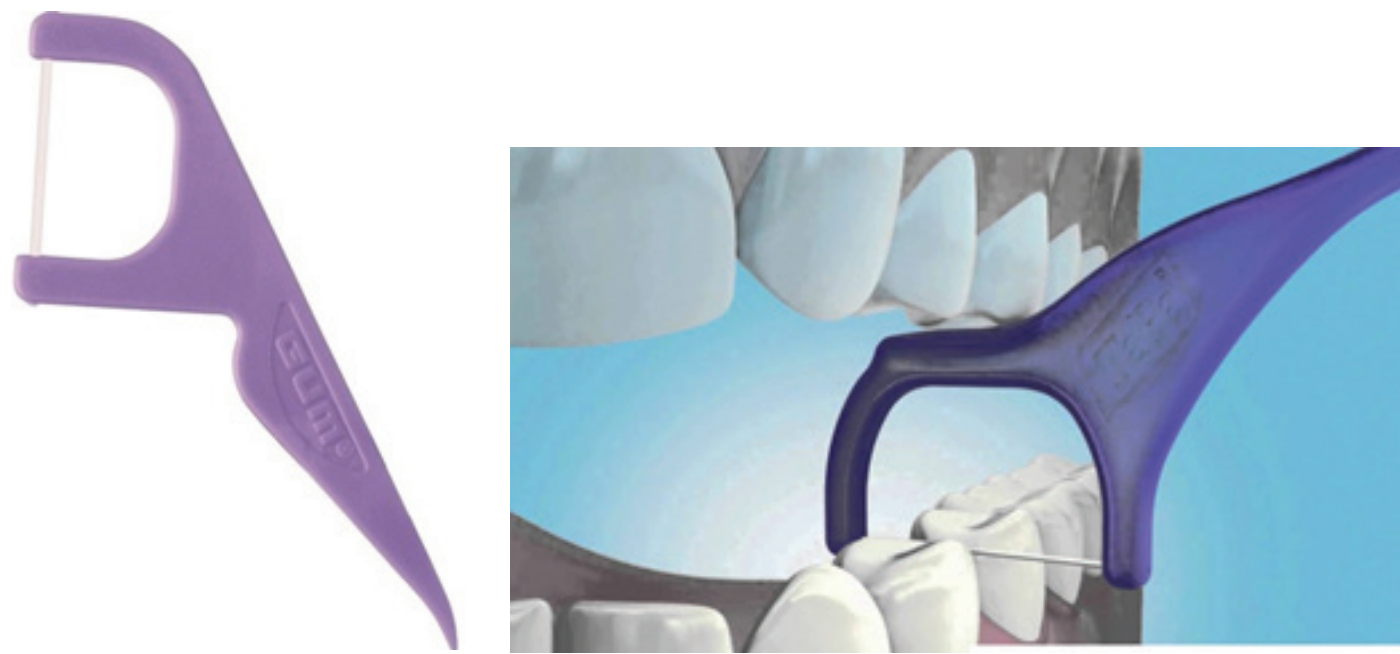

HTTPS://WWW.GOOGLE.COM.BR/IMGRES?IMGURL=HTTP\%3A\%2F\%2FASSETS.XTECHCOMMERCE.COM\%2FUPLOADS\%2FIMAGES\%2FMEDIUM \%2FAEC72D16ECA4E206D2E3263002c15D1D.PNG\&IMGREFURL=HTTP\%3A\%2F\%2FWWW.ORALFARMA.COM.BR\%2FMINI-FLOSSER-

1 - Fio-dental com passador de fio (forquilha) 